ISSN 1507-3858

e-ISSN 2450-0003

\author{
Adam Stecyk \\ Uniwersytet Szczeciński \\ e-mail: adam.stecyk@wzieu.pl
}

\title{
ANALIZA JAKOŚCI WYBRANYCH SYSTEMÓW E-LEARNINGOWYCH ZA POMOCA WIELOKRYTERIALNEJ METODY ANALITYCZNEGO PROCESU DECYZYJNEGO AHP
}

\section{THE MULTI-CRITERIA ANALYTIC HIERARCHY PROCESS (AHP) FOR QUALITY ANALYSIS OF SELECTED E-LEARNING SYSTEMS}

DOI: $10.15611 /$ ie.2018.3.07

Streszczenie: Celem artykułu jest prezentacja raportu z najnowszych badań przeprowadzonych na Wydziale Zarządzania i Ekonomiki Usług (Uniwersytet Szczeciński) na temat analizy poziomu jakości systemów e-learningowych (LAMS i MOODLE). Analizę oparto na wielokryterialnej metodzie analitycznego procesu hierarchicznego (AHP), narzędziu służącemu do określania głównych kryteriów jakości systemów e-learningowych. Przez hierarchiczne uporządkowanie problemu możliwe jest lepsze zrozumienie poziomu jakości, kryteriów, jakie należy zastosować, a także alternatywnych rozwiązań, które należy poddać ewaluacji. Proponowaną koncepcję badawczą można wykorzystać do analizy problemów nauczania elektronicznego, takich jak jakość systemów nauczania i platform e-learning, tryby nauczania czy jakość usług. Zakładając odpowiedni (najlepszy opis charakteru edukacji i jakości) dobór cech opisowych i przekształcenie ich w realne determinanty, koncepcja AHP może być wykorzystana do poprawy decyzji dotyczących zagadnień jakości w szkolnictwie wyższym.

Słowa kluczowe: AHP, e-learning, jakość, szkolnictwo wyższe, edukacja.

Summary: The aim of the article is a presentation of the report of the latest studies carried out at the Faculty of Management and Economics of Services (University of Szczecin, Poland) on analyzing the quality level of e-learning systems (LAMS and MOODLE) The analysis was based on the multi-criteria analytic hierarchy process (AHP) method, a tool that is used for determining the main criteria of e-learning systems quality. By structuring the problem based on the hierarchy, it is possible to better understand the level of quality, the criteria to be used and the alternatives to be evaluated. The proposed research concept can be used to analyze e-learning problems within the framework of specific subjects, such as system quality, teaching modes and service quality. Assuming a proper (the best description of the nature of 
education and quality) selection of descriptive characteristics and transforming them into real determinants, the AHP concept can be used to improve decisions on quality issues in higher education.

Keywords: AHP, e-learning, quality, higher education, education.

\section{Ocena i pomiar jakości systemów e-learningowych}

Podstawowy problem wynikający $\mathrm{z}$ rozwoju cywilizacyjnego dotyczy wiedzy i umiejętności, w jakie zostają wyposażeni przyszli pracownicy, menadżerowie, przedsiębiorcy, i odpowiedzi na pytanie, czy są one adekwatne do potrzeb i wyzwań XXI wieku. Relacja między rynkiem usług edukacyjnych a rynkami pracy stanowi o potencjale społeczno-gospodarczym i rozwojowym danego kraju [Mączyńska 2014]. Z tego punktu widzenia rynek edukacyjny, a co za tym idzie - jakość usług edukacyjnych - stanowią jeden z podstawowych czynników determinujących poziom przewagi konkurencyjnej określonych przedsiębiorstw, organizacji i jednostek funkcjonujących w dynamicznie zmieniającej się rzeczywistości.

Jednym z efektów globalizacji i rozwoju społeczeństwa informacyjnego jest powszechny wzrost świadomości o wartości wykształcenia, a w rezultacie coraz większa świadomość interesariuszy rynku usług edukacyjnych podczas wyboru kierunku kształcenia oraz rozwoju zawodowego. Zarówno studenci podejmujący określoną ścieżkę akademicką, jak i pracownicy wybierający określone szkolenia w głównej mierze kierują się przydatnością zawodową studiów i kursów (zapotrzebowanie rynku pracy, potencjalne wynagrodzenie, wzrost poziomu wiedzy i kompetencji). Coraz częściej ważnym kryterium wyboru w szkolnictwie wyższym jest model nauczania, czyli sposób dystrybuowania wiedzy w kontekście technologicznym, metodycznym, organizacyjnym i społecznym. Może to oznaczać wzrost popytu na edukację, a w szczególności na dobre jakościowo usługi edukacyjne, wykorzystujące technologie ICT (technologie informacyjno-komunikacyjne), bazujące na kształceniu w modelu e-learningu (nauczania elektronicznego) lub blended learningu (nauczania hybrydowego).

Tak zarysowana perspektywa wskazuje na potrzebę jakościowej oceny określonych komponentów edukacyjnych na wszystkich poziomach: od strategii podmiotu edukacyjnego, przez aktualność programów nauczania, aż po ocenę poziomu jakości wykorzystywanych systemów, narzędzi i materiałów dydaktycznych. Ponieważ kwestia oceny jest ściśle związana z problemem pomiaru zidentyfikowanych czynników determinujących poszczególne obszary jakości, zachodzi konieczność budowania modelu na podstawie właściwego doboru istniejących metod, które mogą znaleźć zastosowanie w nauczaniu e-learningowym i blended learningowym. Wybór i dostosowanie metod mają charakter subiektywny i pozostają w gestii badacza analizującego określony obiekt pod względem oceny i pomiaru jakości.

W literaturze przedmiotu można znaleźć wiele teoretycznych modeli oceny jakości i ich aplikacji w postaci metod i technik analitycznych. Do oceny systemów 
i narzędzi e-learningowych ${ }^{1}$ zastosowane mogą być koncepcje oceny jakości bazujące na metodach SERVQUEL i SERVPERF [Parasuraman i in. 1994; Cronin, Taylor 1994; Stecyk 2016], a także metody oparte na modelach oceny poziomu jakości systemów informatycznych i satysfakcji użytkownika, takie jak kompleksowy model oceny opracowany przez W.H. DeLonea i E.R. McLeana [DeLone, McLean 2003] model oceny satysfakcji i kluczowych wymiarów systemów, który opracowali S. Cai, M. Jun oraz L. Pham [Cai i in. 2007], oraz model pomiaru jakości i satysfakcji użytkownika, który przygotowali W.J. Doll i G. Torkzadeh [Doll, Torkzadeh 1988].

Drugą grupą narzędzi mogących mieć zastosowanie podczas oceny jakościowych problemów w obszarach nauczania elektronicznego są metody wielokryterialne. Do najbardziej znanych zalicza się metody ELECTRE (Elimination et Choice Translating Reality) I i II, III i IV [Banayoun i in. 1966] PROMETHEE I i II, MAPPACC, PRAGMA, sztuczne sieci neuronowe [Diech i in. 2000], DEA (Data Envelopment Analysis) [Charnes i in. 1978] czy metoda AHP (Analytic Hierarchy Process) i ANP (Analytic Network Process) [Saaty 2002].

Celem artykułu jest zaprezentowanie praktycznego wykorzystania wielokryterialnej metody analitycznego procesu decyzyjnego (AHP) do eksperckiej oceny poziomu jakości dwóch systemów e-learningowych (MOODLE i LAMS) wykorzystywanych w nauczaniu hybrydowym. W pierwszej kolejności scharakteryzowano główne założenia metodyczne koncepcji analitycznego procesu hierarchicznego AHP, wskazano określone etapy i techniki analityczne umożliwiające empiryczne podejście do badanego problemu, a także weryfikację i interpretację osiągniętych wyników. W kolejnym punkcie dokonano aplikacji metody AHP do oceny jakości dwóch wybranych systemów e-learningowych na Wydziale Zarządzania i Ekonomiki Usług Uniwersytetu Szczecińskiego: LAMS - Learning Activity Management System (od 2007 r.) - oraz jego integracji z systemem MOODLE (od 2009 r.). Wymiernymi efektami przeprowadzonych badań jest zbiór zweryfikowanych kryteriów oceny systemów e-learningowych oraz preferencje dotyczące platformy LAMS i MOODLE.

\section{Charakterystyka metody analitycznego procesu hierarchicznego AHP}

Metoda AHP umożliwia praktyczne zastosowanie wielokryterialnej koncepcji decyzyjnej do postawionego problemu badawczego. Została opracowana w latach siedemdziesiątych ubiegłego wieku i do tej pory znalazła zastosowanie między innymi w takich dziedzinach życia społeczno-gospodarczego, jak ekonomia, zarządzanie, transport, polityka, edukacja, medycyna, technologia. Głównym założeniem metody AHP jest relatywna skala ocen/priorytetów dokonywana za pomocą odwracalnych

\footnotetext{
${ }^{1}$ Niektóre z wymienionych metod wymagają określonych modyfikacji i dostosowania do specyfiki kursów realizowanych w trybie e-learning lub blended learning.
} 
porównań parami zarówno dla policzalnych, jak i niepoliczalnych kryteriów. Rysunek 1 przedstawia modelowe ujęcie metody AHP, na którą składają się następujące etapy:

1. Określenie celu głównego (celu badania, np. decyzji wyboru, ustalenia priorytetów itp.).

2. Wybór podstawowych kryteriów (jeśli badacz uzna to zasadne, także subkryteriów), według których dany problem będzie analizowany.

3. Wybór alternatyw (rozwiązań), które zostaną ocenione według przyjętych kryteriów.

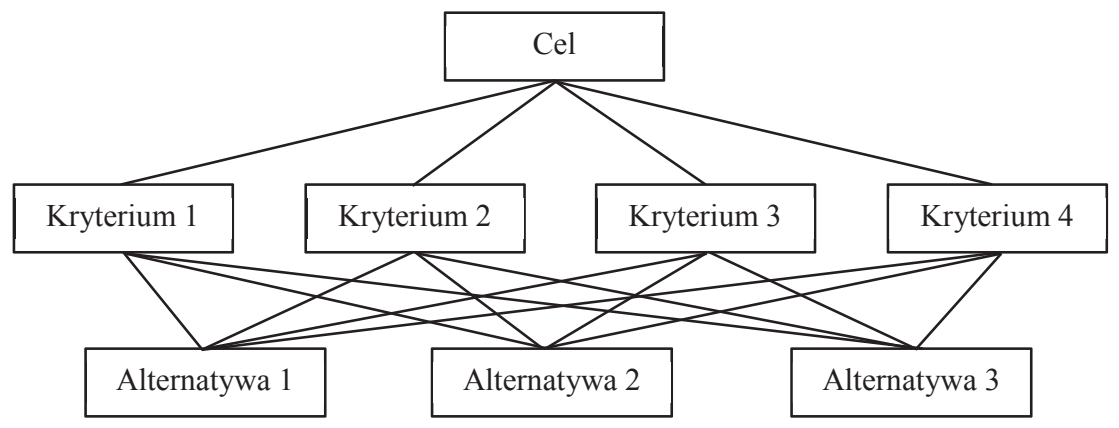

Rys. 1. Hierarchia decyzyjna AHP

Źródło: opracowanie własne na podstawie [Saaty 2002].

4. Zamiana przyjętych czynników na postać numeryczną (za pomocą fundamentalnej skali 1-9) i utworzenie kwadratowej macierzy porównań parami.

5. Utworzenie macierzy znormalizowanej na podstawie wektorów priorytetów i obliczenie: największej wielkości własnej macierzy $\lambda_{\max }$, indeksu niezgodności C.I (odpowiadającego za brak konsekwencji porównań) oraz współczynnika niezgodności C.R. (odpowiadającego za koherencję porównań parami).

6. Obliczenie priorytetów lokalnych (według pkt 4 i 5) dla alternatyw względem każdego kryterium.

7. Opcjonalne wykonanie analizy wrażliwości dającej odpowiedź, jak zmiany wag przypisanych do poszczególnych kryteriów mogą wpływać na końcowy rezultat.

Ważnym elementem metody jest fundamentalna skala Saaty'ego: od 1 do 9, stosowana do oceny poszczególnych kryteriów i alternatyw, która umożliwia wykorzystanie eksperckiej wiedzy i doświadczenia decydenta (lub grupy decydentów). Podstawowym jej celem jest wskazanie, ile razy określony element przeważa nad innym w odniesieniu do ocenianego kryterium. W tabeli 1 przedstawiono główne założenia omawianej skali.

Podstawowym zadaniem ekspertów w metodzie AHP jest dokonanie odwracalnych porównań parami pomiędzy wybranymi kryteriami, dla których $a_{i j}=1 / a_{j i}$ oraz 
Tabela 1. Fundamentalna skala w metodzie AHP

\begin{tabular}{|c|c|c|}
\hline Skala & Definicja & Opis \\
\hline 1 & Równe znaczenie & $\begin{array}{l}\text { Równoważność obu porównywanych elementów (oba elementy } \\
\text { w równym stopniu przyczyniają się do osiągnięcia żądanego celu), } \\
\text { są równoważne }\end{array}$ \\
\hline 3 & $\begin{array}{l}\text { Słaba lub } \\
\text { umiarkowana } \\
\text { przewaga }\end{array}$ & $\begin{array}{l}\text { Słabe (umiarkowane) znaczenie lub preferencja jednego elementu } \\
\text { nad drugim (jeden element ma nieco większe znaczenie niż drugi) }\end{array}$ \\
\hline 5 & Mocna przewaga & Mocna preferencja (znaczenie) jednego elementu nad innym \\
\hline 7 & $\begin{array}{l}\text { Bardzo mocna } \\
\text { (silna) przewaga }\end{array}$ & $\begin{array}{l}\text { Dominujące znaczenie lub bardzo mocna preferencja jednego } \\
\text { elementu nad drugim }\end{array}$ \\
\hline 9 & $\begin{array}{l}\text { Ekstremalna lub } \\
\text { absolutna }\end{array}$ & $\begin{array}{l}\text { Absolutne większe znaczenie (preferencja) jednego elementu } \\
\text { nad drugim (przewaga jednego elementu nad drugim jest na } \\
\text { najwyższym możliwym do określenia poziomie) }\end{array}$ \\
\hline $2,4,6,8$ & $\begin{array}{l}\text { Dla porównań } \\
\text { kompromisowych } \\
\text { między } \\
\text { powyższymi } \\
\text { wartościami }\end{array}$ & $\begin{array}{l}\text { Gdy istnieje potrzeba interpolacji numerycznej kompromisowych } \\
\text { opinii, ponieważ nie ma dobrego słowa do ich opisania (stosowane } \\
\text { są wówczas odpowiednie wartości środkowe z powyższej skali) }\end{array}$ \\
\hline $1,1-1,9$ & $\begin{array}{l}\text { Dla elementów } \\
\text { o bliskim } \\
\text { znaczeniu } \\
\text { (powiązanych) }\end{array}$ & $\begin{array}{l}\text { Jeżeli znaczenia elementów są bliskie i prawie nie do odróżnienia, } \\
\text { to przyjmuje się średnią równą } 1,3 \text {, a ekstremum }=1,9\end{array}$ \\
\hline $\begin{array}{l}\text { Odwrotność } \\
\text { ocen }\end{array}$ & $\begin{array}{l}\text { Tak zwana } \\
\text { przechodniość } \\
\text { ocen }\end{array}$ & $\begin{array}{l}\text { Gdy jeden element został oceniony na x, wówczas drugi, podczas } \\
\text { oceny parami, zostaje oceniony na } 1 / x\end{array}$ \\
\hline
\end{tabular}

Źródło: opracowanie własne na podstawie [Saaty 2002].

$a_{i i}=1$. Oceny eksperckie wpisane zostają do kwadratowej macierzy porównań parami $(n \times n) \mathrm{A}=\left[a_{i j}\right]$, w której wykonuje się $n(n-1) / 2$ tych porównań. Konsekwencją tego jest porównanie parami każdego kryterium za pomocą fundamentalnej skali 1-9 i przypisanie odwrotności oceny dla drugiego elementu². W przypadku ocen grupy ekspertów analizujących określony problem decyzyjny do obliczenia końcowej oceny należy zastosować średnią geometryczną wszystkich ocen eksperckich. Przykład macierzy porównania parami zawiera tab. 2 .

${ }^{2}$ Zaprezentowany sposób oceny parami ma postać klasyczną. Niemniej jednak w metodzie AHP dopuszcza się inne sposoby oceny parami określonych elementów występujących w hierarchii decyzyjnej. Istnieje na przykład możliwość wykorzystania rzeczywistych danych liczbowych oraz danych statystycznych opisujących analizowany problem. W obliczaniu priorytetów można wykorzystać także specjalną aplikację komputerową, np. Super Decisions lub Expert Choice. 
Tabela 2. Przykład porównania parami w metodzie AHP

\begin{tabular}{|c|c|c|c|c|}
\hline Wyszczególnienie & Kryterium 1 & Kryterium 2 & Kryterium 3 & Kryterium 4 \\
\hline Kryterium 1 & 1 & $1 / 7$ & 1 & $1 / 2$ \\
\hline Kryterium 2 & 7 & 1 & $1 / 5$ & $1 / 3$ \\
\hline Kryterium 3 & 1 & 5 & 1 & $1 / 9$ \\
\hline Kryterium 4 & 2 & 3 & 9 & 1 \\
\hline
\end{tabular}

Źródło: opracowanie własne.

Kolejne etapy stosowania metody AHP opierają się na obliczeniu macierzy znormalizowanej dla wybranych kryteriów oraz największej wielkości własnej macierzy $\lambda_{\max }$. Autor metody udowodnił, że porównania parami są tym bardziej konsekwentne, im wartość $\lambda_{\max }$, jest bardziej zbliżona do liczby elementów macierzy $n$. Na tej podstawie zaproponowano obliczenie wartości indeksu niezgodności C.I, według wzoru:

$$
\text { C.I. }=\frac{\lambda_{\max }-n}{n-1}
$$

oraz współczynnika niezgodności C.R.,

$$
C . R .=\frac{100 \% * C . I .}{R . I .}
$$

gdzie R.I to losowy indeks niezgodności, wygenerowany z kilku tysięcy macierzy i zaproponowany przez autora metody w postaci tab. 3 .

Tabela 3. Losowy indeks niezgodności R.I.

\begin{tabular}{|l|c|c|c|c|c|c|c|c|c|c|c|c|c|c|c|c|}
\hline Rząd macierzy & $n$ & 1 & 2 & 3 & 4 & 5 & 6 & 7 & 8 & 9 & 10 & 11 & 12 & 13 & 14 & 15 \\
\hline $\begin{array}{l}\text { Losowy indeks } \\
\text { niezgodności }\end{array}$ & R.I. & 0 & 0 & 0,52 & 0,89 & 1,11 & 1,25 & 1,35 & 1,40 & 1,45 & 1,49 & 1,52 & 1,54 & 1,56 & 1,58 & 1,59 \\
\hline
\end{tabular}

Źródło: [Saaty 2002].

Zakłada się, że wartość C.R. dla macierzy $(3 \times 3)$ i $(4 \times 4)$ powinna być odpowiednia mniejsza lub równa $5 \%$ i $8 \%$, natomiast dla większych macierzy nie powinna przekraczać $10 \%$ (C.R. $\leq 10 \%)$. Przyjmuje się wówczas, że współczynnik niezgodności C.R. jest akceptowany, a dokonane porównania są konsekwentne (zgodne). W przypadku przekroczenia progu $10 \%$ przez współczynnik niezgodności $C . R$. należy powtórzyć ocenę kryteriów w celu pozbycia się niezgodności porównań parami. Kolejnym etapem analizy AHP jest zastosowanie tej samej techniki analitycznej do subkryteriów (jeżeli zostały zidentyfikowane), a w razie ich braku - do zapropono- 
wanych alternatyw, co pozwoli na określenie priorytetów w ramach przyjętej struktury hierarchicznej.

\section{Zastosowanie metody AHP do oceny jakości wybranych systemów e-learningowych}

Doświadczenia w stosowaniu systemów e-learningowych na Wydziale Zarządzania i Ekonomiki Usług Uniwersytetu Szczecińskiego związane są dwoma platformami: LAMS - Learning Activity Management System (2007 r. ), oraz jego integracją z systemem MOODLE (2009 r.). Przez ponad dziesięć lat kwestie metodyczne, organizacyjne, technologiczne i społeczne, związane z wykorzystywaniem omawianych narzędzi (w sposób łączny (integracja) lub rozłączny (systemy niezależne)), umożliwiły identyfikację czynników determinujących jakościową ocenę omawianych narzędzi w określonych obszarach.

Opierając się na koncepcji metody AHP, przyjęto następujące założenia wstępne odnośnie do poziomów hierarchii decyzyjnej do oceny i pomiaru jakości systemu LAMS i MOODLE:

Poziom I. Cel analizy - ocena jakości wybranych systemów e-learningowych.

Poziom II. Kryteria - interfejs (I), administracja (A), funkcjonalność (F, łatwość obsługi), narzędzia prezentacji (P), narzędzia komunikacji (K), narzędzia weryfikacji (W), narzędzia projektowania treści dydaktycznych (D), narzędzia organizacji kursów (O).

Poziom III. Alternatywy - porównanie systemu MOODLE i LAMS.

Podstawowy problem w omawianym badaniu stanowi identyfikacja kluczowych kryteriów determinujących poziom jakości systemów nauczania elektronicznego. Wstępna analiza zagadnienia umożliwiła wyodrębnienie 11 głównych determinant jakości, które poddano weryfikacji przez wykorzystanie kombinacji metod heurystycznych, takich jak: metoda transferu pojęć, metoda definicji, metoda niekompetencji oraz metoda analogii. $\mathrm{W}$ ten sposób pierwotna lista została ograniczona do 8 czynników i stanowiła podstawę do zbudowania macierzy ocen parami. W kolejnym etapie zsumowano wartości w kolumnach i dokonano normalizacji macierzy poprzez podzielenie wszystkich wartości macierzy przez sumę relewantnej kolumny. Następnie obliczono wagi wybranych kryteriów (średnią arytmetyczną dla wszystkich wierszy znormalizowanej macierzy; tab. 4).

W celu obliczenia wartości $\lambda_{\max }$ posłużono się iloczynem wektora wag i nieznormalizowanej macierzy ocen parami, co dało możliwość obliczenia sumy dla poszczególnych wierszy nowej macierzy, które następnie odpowiednio podzielono przez wagi pochodzące z macierzy znormalizowanej. Średnia arytmetyczna uzyskanych wyników dała poszukiwaną wielość wartości $\lambda_{\max }=8,76$.

$\mathrm{W}$ kolejnym etapie obliczono wartość indeksu niezgodności $C . I=0,1085$ oraz współczynnika niezgodności (dla $n=8$, współczynnik $R . I .=1,40) C . R .=0,0775$ (7,75\%). Zgodnie z przyjętymi założeniami współczynnik niezgodności może zo- 
Tabela 4. Znormalizowana macierz ocen parami i wagi dla wybranych kryteriów

\begin{tabular}{|c|c|c|c|c|c|c|c|c|c|}
\hline Wyszczególnienie & $\mathrm{I}$ & $\mathrm{A}$ & $\mathrm{F}$ & $\mathrm{P}$ & $\mathrm{K}$ & $\mathrm{W}$ & $\mathrm{D}$ & $\mathrm{O}$ & Waga \\
\hline $\mathrm{I}$ & 0,05 & 0,06 & 0,04 & 0,47 & 0,04 & 0,02 & 0,22 & 0,16 & 0,13 \\
\hline $\mathrm{A}$ & 0,05 & 0,06 & 0,10 & 0,05 & 0,02 & 0,02 & 0,09 & 0,16 & 0,07 \\
\hline $\mathrm{F}$ & 0,38 & 0,18 & 0,30 & 0,16 & 0,35 & 0,30 & 0,28 & 0,26 & 0,28 \\
\hline $\mathrm{P}$ & 0,16 & 0,18 & 0,30 & 0,16 & 0,35 & 0,30 & 0,16 & 0,16 & 0,22 \\
\hline $\mathrm{K}$ & 0,16 & 0,30 & 0,10 & 0,05 & 0,12 & 0,18 & 0,09 & 0,16 & 0,15 \\
\hline $\mathrm{W}$ & 0,16 & 0,18 & 0,06 & 0,03 & 0,04 & 0,06 & 0,03 & 0,05 & 0,08 \\
\hline $\mathrm{D}$ & 0,01 & 0,02 & 0,03 & 0,03 & 0,04 & 0,06 & 0,03 & 0,02 & 0,03 \\
\hline $\mathrm{O}$ & 0,02 & 0,02 & 0,06 & 0,05 & 0,04 & 0,06 & 0,09 & 0,05 & 0,05 \\
\hline
\end{tabular}

Źródło: opracowanie własne.

stać zaakceptowany (jest mniejszy niż 10\%), co oznacza, że przeprowadzone w ramach przyjętych kryteriów porównania są zgodne.

Na tym etapie analizy można wnioskować o ważności poszczególnych kryteriów dla decydentów do oceny jakości systemów e-learningowych. Najważniejszym kryterium w omawianym badaniu jest funkcjonalność $(F=0,28)$ i narzędzia prezentacji $(P=0,22)$; najmniej istotne to narzędzia projektowania treści dydaktycznych $(D=0,03)$ i narzędzia organizacji kursów $(O=0,05)$. Na rysunku 2 zaprezentowano wagi dla wybranych kryteriów w ocenie jakości systemów nauczania elektronicznego.

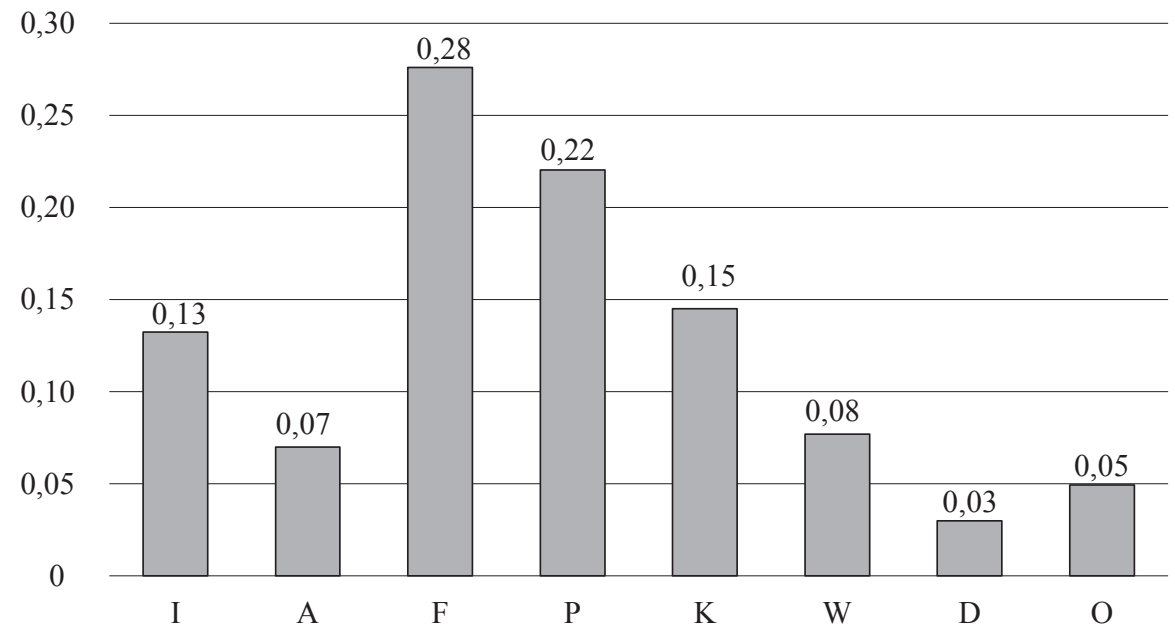

Rys. 2. Wagi wybranych kryteriów w ocenie jakości systemów e-learningowych Źródło: opracowanie własne. 
Kolejnym etapem analizy jest obliczenie tzw. priorytetów lokalnych dla wybranych alternatyw (LAMS i MOODLE) względem ośmiu wybranych kryteriów. Ponieważ technikę analityczną zaprezentowano w odniesieniu do poziomu kryteriów, w tym miejscu zostanie przedstawiony sposób obliczenia priorytetów lokalnych dla najważniejszego kryterium, czyli dla funkcjonalności, i wyniki końcowe dla pozostałych kryteriów (tab. 5-7).

Tabela 5. Porównanie alternatyw w odniesieniu do kryterium funkcjonalności

\begin{tabular}{|l|c|c|}
\hline \multicolumn{1}{|c|}{ Funkcjonalność } & LAMS & MOODLE \\
\hline LAMS & 1 & 5 \\
\hline MOODLE & $1 / 5=0,2$ & 1 \\
\hline Suma & 1,2 & 6 \\
\hline
\end{tabular}

Źródło: opracowanie własne.

Tabela 6. Priorytety lokalne dla kryterium funkcjonalności

\begin{tabular}{|l|c|c|c|}
\hline \multicolumn{1}{|c|}{ Funkcjonalność } & LAMS & MOODLE & Priorytety \\
\hline LAMS & 0,83 & 0,83 & 0,83 \\
\hline MOODLE & 0,17 & 0,17 & 0,17 \\
\hline
\end{tabular}

Źródło: opracowanie własne.

Tabela 7. Priorytety lokalne dla wszystkich kryteriów i końcowe preferencje

\begin{tabular}{|l|l|l|l|l|l|l|l|l|l|}
\hline $\begin{array}{l}\text { Wyszcze- } \\
\text { gólnienie }\end{array}$ & \multicolumn{1}{|c|}{$\mathrm{I}$} & $\mathrm{A}$ & $\mathrm{F}$ & $\mathrm{P}$ & $\mathrm{K}$ & $\mathrm{W}$ & $\mathrm{D}$ & \multicolumn{1}{|c|}{$\mathrm{O}$} & \multicolumn{1}{|c}{} \\
\hline Waga & $\mathbf{0 , 1 3}$ & $\mathbf{0 , 0 7}$ & $\mathbf{0 , 2 8}$ & $\mathbf{0 , 2 2}$ & $\mathbf{0 , 1 5}$ & $\mathbf{0 , 0 8}$ & $\mathbf{0 , 0 3}$ & $\mathbf{0 , 0 5}$ & Suma \\
\hline LAMS & 0,0858 & 0,0175 & 0,2324 & 0,055 & 0,024 & 0,02 & 0,00375 & 0,0083 & $\mathbf{0 , 4 4 7}$ \\
\hline MOODLE & 0,0429 & 0,0525 & 0,0476 & 0,165 & 0,1245 & 0,06 & 0,02625 & 0,04165 & $\mathbf{0 , 5 6 0}$ \\
\hline
\end{tabular}

Źródło: opracowanie własne.

Budowa ośmiu znormalizowanych macierzy preferencji alternatyw (LAMS i MOODLE) umożliwiła obliczenie priorytetów lokalnych względem każdego kryterium. Następnie obliczono priorytety ważone (iloczyn priorytetów lokalnych i wag kryteriów), co w konsekwencji umożliwiło obliczenie wyników końcowych preferencji (suma).

\section{Wnioski}

Przeprowadzona analiza wielokryterialna metodą analitycznego procesu decyzyjnego AHP dała odpowiedź na pytanie o poziom jakości dwóch systemów e-learningowych (LAMS i MOODLE), ocenianych względem siebie i względem ośmiu 
wybranych kryteriów. Wyniki wskazują na nieznaczne preferowanie przez decydentów systemu MOODLE (56\%) wobec systemu LAMS (44\%). Ponadto wskazała poziom istotności wybranych kryteriów. Omówione badanie może stanowić punkt wyjścia do dalszych, pogłębionych analiz, np. poprzez wykonanie analizy wrażliwości i zmian wag poszczególnych kryteriów względem siebie.

Reasumując zaprezentowane rozważania, należy zaznaczyć, że przyjęcie określonych założeń metodologicznych w odniesieniu do badanego problemu uwzględniało wszystkie trudności i niedoskonałości metody (złożoność problemu, brak uniwersalnych metod, problem trafności i rzetelności doboru kryteriów i ich oceny itp.). Stwierdzenie to jest zgodne z tezą K. Poppera: dla metody empirycznej charakterystyczne jest to, że system podlegający sprawdzaniu dostępny jest falsyfikacji na wszystkie dające się pomyśleć sposoby. Cel tej metody (metody możliwości obalenia) nie polega na ratowaniu życia nie dających się utrzymać systemów, lecz przeciwnie - na rzuceniu ich wszystkich w wir najzacieklejszej walki o przetrwanie i wybraniu tego, który w porównaniu z innymi okaże się najlepiej przystosowany [Popper 2002]. Tak zarysowana perspektywa wskazuje na konieczność ciągłego doskonalenia metod i modeli służących do pomiaru i oceny wykorzystywanych systemów nauczania elektronicznego w celu zrozumienia wpływu technologii na inne sfery życia społeczno-gospodarczego.

\section{Literatura}

Alonso F., 2005, An instructional model for webbased e-learning education with a blended learning process approach, British Journal of Educational Technology, s. 217-235.

Banayoun R., Roy B., Sussman N., 1966, Manual de Reference du Programme Electre, Note de Synthese et Formation 25, Direction Scientifique SEMA.

Cai S., Jun M., Pham L., 2007, End-user computing satisfaction and its key dimensions: An exploratory study, Southwest Decision Sciences Institute, s. 725-734.

Charnes A., Cooper W., Rhodes E., 1978, Measuring the efficiency of decision making units, European Journal of the Operational Research, nr 2, s. 63-85.

Cronin J., Taylor S., 1994, SERPVERF Versus SERVQUAL: Reconciling Performance-Based and Perceptions - Minus-Expectations Measurement of Service quality, Journal of Marketing, nr 58(1), s. 23-24.

DeLone W.H., McLean E.R., 2003, The DeLone and McLean model of information systems success: A ten-year update, Management Information Systems, 19(4), s. 9-30.

Diech W., Korbicz J., Rutkowski L., Tadeusiewicz R., 2000, Sieci neuronowe, Akademicka Oficyna Wydawnicza EXIT, Warszawa.

Doll W.J., Torkzadeh G., 1988, The measurement of end-user computing satisfaction, MIS Quarterly, $12: 2$, s. $259-274$.

Education, 2010, US Department of Education, https://www2.ed.gov/rschstat/eval/tech/evidencebased-practices/finalreport.pdf.

Mączyńska M., 2014, Polska transformacja a kapitalizm inkluzywny, Mazowsze. Studia Regionalne, nr 15, s. 13-18.

Mizerek H., 2012, Jakość edukacji. Dyskursy, które wybrzmiały, milcząc, [w:] Jakość edukacji, różnorodne perspektywy, Wydawnictwo Uniwersytetu Jagiellońskiego, Kraków, s. 13-16. 
Nedelcu B., 2015, Business intelligence systems, Database Journal, 1/12.

Olszak C.M., 2012, Analiza i ocena dorobku naukowego z zakresu Business Intelligence, [w:] Olszak C.M., Systemy inteligencji biznesowej jako przedmiot badań ekonomicznych, Wydawnictwo Uniwersytetu Ekonomicznego w Katowicach, Katowice, s. 11-26.

Parasuraman A., Zeithaml V., Berry L., 1994, Alternative scales for measuring service quality: A comparative assessment based on psychometric and diagnistic criteria, Journal of Marketing 1994, nr 70 (3), s. 201-230.

Picciano A.G., 2014, Blended Learning: Research Perspectives, Taylor \& Francis, New York.

Popper K., 2002, Logika odkrycia naukowego, Wydawnictwo Naukowe PWN, Warszawa.

Rudawska E., Kiecko R., 2000, SERVQUAL - metoda badania jakości usług i jej praktyczne zastosowanie, Marketing i Rynek, nr 5, s. 12-13.

Saaty R., 2002, Decision Making in Complex Environments: The Analytic Network Process (ANP) for Dependence and Feedback: A Manual for the ANP Software SuperDecisions, Creative Decisions Foundation.

Scott T., 2003, Bloom's taxonomy applied to testing in computer science classes, Journal of Computing Sciences in Colleges, s. 267-274.

Stecyk A., 2016, Doskonalenie jakości ustug edukacyjnych w szkolnictwie wyższym. Podejście metodyczne, Uniwersytet Szczeciński, Szczecin.

Tijssen R.J., 1998, Quantitative assessment of large heterogeneous R\&D networks: The case of Process Engineering in the Netherlands, Research Policy, 26, s. 7-8.

Wells D., 2008, Business Analytics - Getting the Point, http://b-eye-network.com/view/7133. 